Review began 11/18/2021 Review ended 12/02/2021 Published 12/03/2021

๑) Copyright 2021

Al Sulmi et al. This is an open access article distributed under the terms of the Creative Commons Attribution License CCBY 4.0., which permits unrestricted use, distribution, and reproduction in any medium, provided the original author and source are credited.

\section{Awareness, Perceptions, and Desirability of Epidural Analgesia Among Pregnant Women in King Fahad University Hospital, Al Khobar}

Eman S. Al Sulmi ${ }^{1}$, Manar M. Al Yousef ${ }^{2}$, Jenan A. Almuslim ${ }^{2}$, Rawan A. Al Muslim ${ }^{2}$, Zahra A. Amailo ${ }^{2}$, Fatimah A. Alabbad ${ }^{2}$

1. Obstetrics and Gynecology, King Fahad University Hospital, Al Khobar, SAU 2. Medicine, Imam Abdulrahman Bin Faisal University, Dammam, SAU

Corresponding author: Jenan A. Almuslim, jenan.almuslim@gmail.com

\begin{abstract}
Background: Childbirth is a normal life event that is considered to have the most severe pain faced by women in their lifetime. However, this pain can be managed in many ways such as using epidural analgesia (EDA).
\end{abstract}

Objective: This study focuses on assessing the awareness, perceptions, and desirability of EDA among pregnant women at King Fahad University Hospital (KFUH), Al Khobar.

Methods: A cross-sectional study was conducted at KFUH in Al Khobar, Eastern Province of Saudi Arabia. The study took place from November to December 2020 by using a pre-designed questionnaire developed by the researchers based on a thorough literature review of prior studies. A total of 209 pregnant females participated in the study. The study included all pregnant women attending antenatal clinics and the emergency room at KFUH and we excluded postpartum women from the study.

Results: A total of 209 pregnant women participated in this two-month study and completed the questionnaire. The majority of women were between the age of $30-35$ years old (33\%), while a few (16\%) were less than 24 years. The patient's perception was found to be significantly influenced by age and household income. On the other hand, awareness of EDA complications and desirability was seen to be associated with income.

Conclusion: Study results demonstrate that the majority of pregnant women were aware, as well as had a positive perception and desirability toward using EDA for labor pain. On the other hand, pregnant women who had a lack of awareness and perception toward EDA may suffer more from labor pain, which will negatively affect their birth experience and may make it less enjoyable. Therefore, education about different types of analgesia, especially EDA, should be included in an antenatal care program.

Categories: Anesthesiology, Obstetrics/Gynecology, Pain Management

Keywords: perception, labor, epidural, awareness, analgesia

\section{Introduction}

Childbirth is a normal life event that is considered to have the most severe pain faced by women in their lifetime. This pain is manageable and can be influenced by medications and many other factors including age and psychological factors such as anxiety, emotional support, educational level, culture, and ethnicity [1]. Epidural analgesia (EDA) is considered an effective measure for labor pain relief if administered timely [2]. EDA allows women to rest if the labor is prolonged, and remain an active participant in the child birthing [3]. If instrumental delivery is needed, EDA will help to decrease the discomfort, and if a cesarean section (CS) is required it allows to stay awake during the procedure. Moreover, using EDA helps to avoid opioidinduced maternal and neonatal respiratory depression [4]. A systematic review study, conducted in 2020, concludes that the early administration of EDA does not increase the risk of proceeding CS, prolong the second stage of labor, or impact maternal and neonatal outcomes [5]. American College of Obstetricians and Gynecologists (ACOG) recommends the use of analgesia in labor when possible [6]. The National Institute for Clinical Excellence has encouraged patients' education on the availability and effectiveness of labor pain options, hence, ensuring that pregnant women have the choice of adequate pain management in labor [7]. EDA is proven an effective and safe option for optimal labor pain management $[2,4]$. Therefore, it is imperative to assess the perception and acceptability of our population to EDA in order to educate and correct misconceptions. Therefore, we conducted this study to assess pregnant women's awareness, perception, and desirability of the usage of EDA, and to identify the reasons for giving birth without epidural analgesia.

\section{Materials And Methods}




\section{Cureus}

\section{Methods}

The study aims to assess the awareness, perception, and desirability of epidural analgesia among pregnant women, identify the reasons for giving birth without epidural analgesia, and the predictors for epidural analgesia requests among pregnant women at a single center in Saudi Arabia. With the approval (IRB-UGS2020-01-291) of Imam Abdulrahman bin Faisal University IRB, a cross-sectional study was conducted at King Fahad University Hospital (KFUH) in Al Khobar, Eastern Province of Saudi Arabia using a selfadministered questionnaire. The questionnaire is divided into eight sections including demographic characteristics, frequency of EDA usage and history of exposure, experience of labor, perception of EDA, awareness of EDA, awareness of complications of EDA in labor, desirability, and source and adequacy of the information. Both paper-based and electronic versions of the questionnaire, according to patients' convenience, were offered to all pregnant women attending antenatal clinics and obstetrics' emergency room excluding postpartum women. With the corona virus disease 2019 (COVID-19) restrictions and reduction in number of clinic visits to maintain social distancing, an average of seven women per day was expected to agree to participate in the study. Thus, 308 women are expected to participate in the two months period. The questionnaire was developed by the researchers based on a thorough literature review of prior studies $[2,8,9]$. It was developed in English then translated to Arabic. The English version was provided for non-Arabic patients. A pilot study for both the Arabic and English version validation was performed on 10 participants who weren't included in the study and changes were made accordingly. The data collectors explained the study to candidates, after agreeing on participation, and signed consent was taken from all participants before they were given the self-administered questionnaire to complete.

\section{Data analysis}

The data were presented as frequency tables for categorical variables. Chi-squared test was used to compare demographics as an independent variable (Age, Nationality, Income, and Parity) with perception, awareness, and desirability of EDA as dependent variables. The questionnaire was assessed and showed that Cronbach's Alpha is 0.859 which means it is statistically reliable.

The result in terms of awareness, perception and desirability, were interpreted using the mean as follows: from 1 to 2 considered to be positive, and from 2.1 to 3 considered to be negative. Results with p-values below 0.05 were considered to be statistically significant. All data analyses were performed in IBM SPSS Statistics for Windows, Version 26.0 (Released 2019, IBM Corp, Armonk, New York).

\section{Results}

For a two-month study period, a total of 209 pregnant women participated in this study with a participation rate of $67.5 \%$. Some of the participants completed the questionnaire but there were also some missing data. The majority of women were between the age of $25-35$ years old (62\%) and predominantly Saudi (80.6\%). Moreover, approximately half of the respondents' income was less than 8000 Saudi Riyal (SAR) (49.8\%). The majority (80.6\%) of our participants had given at least one birth in the past, and only $19.3 \%$ were nulliparous. Table 1 gives the details. 


\section{Cureus}

\begin{tabular}{|c|c|c|}
\hline \multirow{2}{*}{ Factors } & \multicolumn{2}{|c|}{ Descriptive statistics } \\
\hline & Number (N) & Percentage (\%) \\
\hline \multicolumn{3}{|l|}{ Age } \\
\hline $15-19$ years old & 11 & 5.5 \\
\hline $20-24$ years old & 22 & 11.0 \\
\hline $25-29$ years old & 58 & 29.0 \\
\hline 30-35 years old & 66 & 33.0 \\
\hline$>35$ years old & 43 & 21.5 \\
\hline \multicolumn{3}{|l|}{ Nationality } \\
\hline Non-Saudi & 40 & 19.4 \\
\hline Saudi & 166 & 80.6 \\
\hline \multicolumn{3}{|l|}{ Income } \\
\hline$<8000$ SAR & 100 & 49.8 \\
\hline 8000-20000SAR & 72 & 35.8 \\
\hline$>$ 20000SAR & 29 & 14.4 \\
\hline \multicolumn{3}{|l|}{ Parity } \\
\hline None & 40 & 19.3 \\
\hline One birth & 52 & 25.1 \\
\hline Two to four births & 93 & 44.9 \\
\hline More than five births & 22 & 10.6 \\
\hline
\end{tabular}

\section{TABLE 1: Demographic characteristics}

SAR: Saudi Riyal

Out of the 209 women who participated in the questionnaire, only 68 (32.7\%) used epidural analgesia in their previous labor. Fifty-two participants reported a negative experience in the form of either developing side effects or complications such as inadequate analgesia and back pain (39.7\% and 36.8\%, respectively). On the other hand, $76.8 \%$ of women who had used epidural analgesia reported a satisfactory experience. Only $28.6 \%$ of the women who did not use epidural analgesia in the previous labor are willing to use it in the future. The reasons for rejection were mostly due to fear of side effects (40\%). See Table 2. 


\section{Cureus}

\begin{tabular}{|c|c|c|}
\hline \multirow{2}{*}{ Question } & \multicolumn{2}{|c|}{ Descriptive statistics } \\
\hline & Number $(\mathrm{N})$ & Percentage (\%) \\
\hline \multicolumn{3}{|c|}{ Have you ever had epidural analgesia? } \\
\hline No & 140 & 67.3 \\
\hline Yes & 68 & 32.7 \\
\hline \multicolumn{3}{|c|}{ Did you develop any side effects? } \\
\hline No & 41 & 60.3 \\
\hline Yes & 27 & 39.7 \\
\hline \multicolumn{3}{|c|}{ Did you develop any complication? } \\
\hline No & 43 & 63.2 \\
\hline Yes & 25 & 36.8 \\
\hline \multicolumn{3}{|c|}{ What was your experience from using epidural analgesia in labor? } \\
\hline Satisfied & 53 & 76.8 \\
\hline Not satisfied & 15 & 21.7 \\
\hline Not available & 1 & 1.4 \\
\hline \multicolumn{3}{|c|}{ Would you like to use epidural analgesia in future? } \\
\hline No & 38 & 27.1 \\
\hline Yes & 40 & 28.6 \\
\hline Unsure & 52 & 37.1 \\
\hline Not available & 10 & 7.1 \\
\hline \multicolumn{3}{|c|}{ Reason for rejecting epidural analgesia } \\
\hline Culture & 2 & 1.4 \\
\hline Fear of side effects & 56 & 40.0 \\
\hline I want natural & 9 & 6.4 \\
\hline Expensive & 4 & 2.9 \\
\hline I have no reason & 38 & 27.1 \\
\hline Not available & 31 & 22.1 \\
\hline
\end{tabular}

\section{TABLE 2: Frequency of epidural usage and history of exposure}

Although pregnant women who already used EDA reported positive perception, awareness, and awareness of complications of EDA, the relation between previous use of EDA with the perception, awareness, and awareness of complications of EDA was statistically insignificant ( $p$-value $=0.503,0.616,0.335$ respectively).

Around $56 \%$ of participants were worried about losing the ability of sensation when they need to push; however, half of them have a positive perception of EDA and agreed that the benefits outweigh the risks of potential side effects. See Table 3. 


\section{Cureus}

\section{Description $(n=209)$}

Percentage

Number

The benefits of pain relief outweigh the risk of side effects with EDA

$\begin{array}{lcc}51.2 \% & 107 & \text { Agree } \\ 14.8 \% & 31 & \text { Disagree } \\ 34.0 \% & 71 & \text { Unsure } \\ \text { I am worried about the possibility of more complications happening with the labor if using EDA } & \\ 67.0 \% & 140 & \text { Agree } \\ 16.3 \% & 34 & \text { Disagree } \\ 16.7 \% & 35 & \text { Unsure } \\ \text { I would NEVER have an EDA } & & \text { Agree } \\ 30.0 \% & 62 & \text { Disagree } \\ 35.7 \% & 74 & \text { Unsure } \\ 34.3 \% & 71 & \end{array}$

I am worried that I might not be able to feel when I need to push

$\begin{array}{lcc}56.5 \% & 118 & \text { Agree } \\ 18.7 \% & 39 & \text { Disagree } \\ 24.9 \% & 52 & \text { Unsure }\end{array}$

I am worried that I may lose control of my urination

$\begin{array}{lcc}45.9 \% & 96 & \text { Agree } \\ 24.9 \% & 52 & \text { Disagree } \\ 29.2 \% & 61 & \text { Unsure }\end{array}$

\section{TABLE 3: Perception of EDA}

EDA: Epidural Analgesia

The patient's perception is significantly associated with age (p-value 0.049). In other words, the majority of women with a positive perception toward EDA were in the age group of 30-35 years (33.7\%). Similar results were found between income and perception, which were statistically significant; participants with low income (<8000SAR) showed more positive perceptions regarding the use of EDA for labor pain. However, parity and nationality did not significantly affect the women's perception of EDA. See Table 4 .

\begin{tabular}{|c|c|c|c|c|c|c|c|c|c|c|c|c|c|}
\hline \multirow{2}{*}{ Variable } & & \multicolumn{3}{|c|}{ Awareness of EDA } & \multicolumn{3}{|c|}{$\begin{array}{l}\text { Awareness of complications of EDA } \\
\text { in labor }\end{array}$} & \multicolumn{3}{|c|}{ Perception of EDA } & \multicolumn{3}{|c|}{ Desirability } \\
\hline & & Positive & Negative & $\begin{array}{l}p- \\
\text { value }\end{array}$ & Positive & Negative & p-value & Positive & Negative & value & Positive & Negative & value \\
\hline \multicolumn{14}{|l|}{ Age } \\
\hline \multirow{2}{*}{$15-19$ years old } & $\mathrm{N}$ & 8 & 3 & & 11 & 0 & & 11 & 0 & & 8 & 3 & \\
\hline & $\%$ & 4.7 & 10.7 & & 6.8 & 0.0 & & 6.3 & 0.0 & & 6.3 & 4.3 & \\
\hline \multirow{2}{*}{ 20-24 years old } & $\mathrm{N}$ & 20 & 2 & & 18 & 4 & & 20 & 2 & & 14 & 8 & \\
\hline & $\%$ & 11.6 & 7.1 & & 11.1 & 10.5 & & 11.4 & 8.0 & & 10.9 & 11.4 & \\
\hline & $\mathrm{N}$ & 52 & 6 & & 51 & 7 & & 53 & 5 & & 37 & 20 & \\
\hline
\end{tabular}




\section{Cureus}

\begin{tabular}{|c|c|c|c|c|c|c|c|c|c|c|c|c|c|}
\hline $25-29$ years old & $\%$ & 30.2 & 21.4 & 0.544 & 31.5 & 18.4 & 0.087 & 30.3 & 20.0 & 0.049 & 28.9 & 28.6 & 0.982 \\
\hline \multirow{2}{*}{$30-35$ years old } & $\mathrm{N}$ & 55 & 11 & & 52 & 14 & & 59 & 7 & & 41 & 24 & \\
\hline & $\%$ & 32.0 & 39.3 & & 32.1 & 36.8 & & 33.7 & 28.0 & & 32.0 & 34.3 & \\
\hline \multirow{2}{*}{$>35$ years old } & $\mathrm{N}$ & 37 & 6 & & 30 & 13 & & 32 & 11 & & 28 & 15 & \\
\hline & $\%$ & 21.5 & 21.4 & & 18.5 & 34.2 & & 18.3 & 44.0 & & 21.9 & 21.4 & \\
\hline \multicolumn{14}{|l|}{ Nationality } \\
\hline \multirow{2}{*}{ Non-Saudi } & $\mathrm{N}$ & 31 & 9 & \multirow{4}{*}{0.113} & 35 & 5 & \multirow{4}{*}{0.218} & 37 & 3 & \multirow{4}{*}{0.277} & 30 & 9 & \multirow{4}{*}{0.066} \\
\hline & $\%$ & 17.6 & 30.0 & & 21.1 & 12.5 & & 20.6 & 11.5 & & 22.9 & 12.3 & \\
\hline \multirow{2}{*}{ Saudi } & $N$ & 145 & 21 & & 131 & 35 & & 143 & 23 & & 101 & 64 & \\
\hline & $\%$ & 82.4 & 70.0 & & 78.9 & 87.5 & & 79.4 & 88.5 & & 77.1 & 87.7 & \\
\hline \multicolumn{14}{|l|}{ Income } \\
\hline \multirow{2}{*}{$<8000$ SAR } & $\mathrm{N}$ & 83 & 17 & \multirow{6}{*}{0.349} & 88 & 12 & \multirow{6}{*}{0.012} & 90 & 10 & & 54 & 45 & \multirow{6}{*}{0.009} \\
\hline & $\%$ & 48.0 & 60.7 & & 55.0 & 29.3 & & 51.1 & 40.0 & & 42.2 & 63.4 & \\
\hline \multirow{2}{*}{$\begin{array}{l}8000- \\
\text { 20000SAR }\end{array}$} & N & 63 & 9 & & 52 & 20 & & 65 & 7 & & 51 & 21 & \\
\hline & $\%$ & 36.4 & 32.1 & & 32.5 & 48.8 & & 36.9 & 28.0 & 0.028 & 39.8 & 29.6 & \\
\hline \multirow{2}{*}{$>$ 20000SAR } & N & 27 & 2 & & 20 & 9 & & 21 & 8 & & 23 & 5 & \\
\hline & $\%$ & 15.6 & 7.1 & & 12.5 & 22.0 & & 11.9 & 32.0 & & 18.0 & 7.0 & \\
\hline \multicolumn{14}{|l|}{ Parity } \\
\hline \multirow{2}{*}{ None } & $\mathrm{N}$ & 36 & 4 & \multirow{8}{*}{0.702} & 32 & 8 & \multirow{8}{*}{0.858} & 35 & 5 & & 21 & 19 & \multirow{8}{*}{0.140} \\
\hline & $\%$ & 20.2 & 13.8 & & 19.2 & 20.0 & & 19.3 & 19.2 & & 16.0 & 25.7 & \\
\hline \multirow{2}{*}{ One birth } & $\mathrm{N}$ & 43 & 9 & & 44 & 8 & & 49 & 3 & & 30 & 20 & \\
\hline & $\%$ & 24.2 & 31.0 & & 26.3 & 20.0 & & 27.1 & 11.5 & & 22.9 & 27.0 & \\
\hline \multirow{2}{*}{$\begin{array}{l}\text { Two to four } \\
\text { births }\end{array}$} & $\mathrm{N}$ & 81 & 12 & & 74 & 19 & & 78 & 15 & 0.350 & 67 & 26 & \\
\hline & $\%$ & 45.5 & 41.4 & & 44.3 & 47.5 & & 43.1 & 57.7 & & 51.1 & 35.1 & \\
\hline \multirow{2}{*}{$\begin{array}{l}\text { more than five } \\
\text { births }\end{array}$} & $\mathrm{N}$ & 18 & 4 & & 17 & 5 & & 19 & 3 & & 13 & 9 & \\
\hline & $\%$ & 10.1 & 13.8 & & 10.2 & 12.5 & & 10.5 & 11.5 & & 9.9 & 12.2 & \\
\hline
\end{tabular}

TABLE 4: Association between awareness of EDA, awareness of EDA complications, perception and desirability toward EDA, and socio-demographic characters

EDA: Epidural Analgesia; N: Number

Data on the awareness of epidural analgesia (Table 5) showed that $69.4 \%$ of women were aware of the technique of EDA. Unfortunately, 22\% of the women thought that EDA was not available in our institution. In addition, just as the details of the technique are important, knowing the profession of the provider of EDA is important as well. More than half the women (73.8\%) agreed that not any healthcare worker can provide them with EDA. In regard to the misconception that EDA may increase the risk of caesarian delivery, in this study there was a clear confusion regarding this issue as $41.1 \%$ were unsure about the answer while $31.4 \%$ disagreed. Concerning lower limb weakness and paraplegia, analysis of the result showed that most of the answers agreed with both of the misconceptions ( $45.5 \%$ and $42.1 \%$ respectively). EDA is used to help the women to deliver with less pain; however, $42.6 \%$ of the women agreed that contractions become weak or stop completely after the administration of EDA. 
Cureus

Percentage

Number

I am aware of EDA for labor pain

$77.5 \%$

$3.3 \%$

$19.1 \%$

Are you aware it is provided in $\mathrm{KFUH}$ ?

$62.2 \%$

130

162

7

40

$9.6 \%$

20

58
Response

Agree

Disagree

Unsure

Agree

Disagree

Unsure

EDA is the administration of a local anesthetic through a catheter into the epidural space of the spine

$69.4 \%$

145

Agree

$3.3 \%$

7

Disagree

$27.3 \%$

57

Unsure

EDA is one of the best forms of pain relief in labor

$68.8 \%$

143

Agree

$5.8 \%$

12

Disagree

$25.5 \%$

53

Unsure

Any healthcare worker can perform EDA

$8.7 \%$

18

Agree

$73.8 \%$

152

Disagree

$17.5 \%$

36

Unsure

EDA increases the probability of C-section

$27.5 \%$

57

Agree

$31.4 \%$

65

Disagree

$41.1 \%$

85

Unsure

EDA may cause lower limb weakness

$45.5 \%$

95

Agree

$23.9 \%$

50

Disagree

$30.6 \%$

64

Unsure

EDA causes paraplegia

$42.1 \%$

88

Agree

$25.4 \%$

53

Disagree

$32.5 \%$

68

Unsure

Contractions become weak or stop completely after administration

$42.6 \%$

89

Agree

$19.6 \%$

41

Disagree

$37.8 \%$

79

Unsure

EDA reduces labor pain and allows the mother to push when needed

$57.4 \%$

120

Agree

2021 Al Sulmi et al. Cureus 13(12): e20146. DOI 10.7759/cureus.20146

7 of 11 


\section{Cureus}

\section{TABLE 5: Awareness of EDA}

EDA: Epidural Analgesia; C-section: Cesarean Section; KFUH: King Fahad University Hospital

Awareness of EDA complications was assessed by asking about the common complication of EDA (Table 6). Most of the women $(n=120 ; 57.4 \%)$ agreed that it causes back pain followed by headache ( $n=96 ; 45.9 \%)$, low blood pressure ( $n=77 ; 36.8 \%)$, increased intervention in labor $(n=63 ; 30.1 \%)$, and finally prolongation of second-stage labor and effect on the unborn baby $(n=61 ; 29.2 \%)$. There was positive awareness of EDA complications, which was associated with income. The result revealed that 55\% of participants' income was less than 8000SAR. The p-value result from studying the association between income and awareness of complications of EDA was found to be significant at 0.012. On the other hand, data showed that there is no significant association between age, nationality, parity, and awareness of EDA complications (Table 4).

\begin{tabular}{|c|c|c|}
\hline \multicolumn{2}{|c|}{ Description ( $n=209)$} & \multirow{2}{*}{ Response } \\
\hline Percentage & Number & \\
\hline \multicolumn{3}{|c|}{ EDA cause back pain } \\
\hline $57.4 \%$ & 120 & Agree \\
\hline $14.4 \%$ & 30 & Disagree \\
\hline $28.2 \%$ & 59 & Unsure \\
\hline \multicolumn{3}{|c|}{ EDA cause headache } \\
\hline $45.9 \%$ & 96 & Agree \\
\hline $15.8 \%$ & 33 & Disagree \\
\hline $38.3 \%$ & 80 & Unsure \\
\hline \multicolumn{3}{|c|}{ EDA increased intervention in labor } \\
\hline $30.1 \%$ & 63 & Agree \\
\hline $19.6 \%$ & 41 & Disagree \\
\hline $50.2 \%$ & 105 & Unsure \\
\hline \multicolumn{3}{|c|}{ EDA cause low blood pressure } \\
\hline $36.8 \%$ & 77 & Agree \\
\hline $15.3 \%$ & 32 & Disagree \\
\hline $47.8 \%$ & 100 & Unsure \\
\hline \multicolumn{3}{|c|}{ EDA cause prolongation of second-stage labor and effect on the unborn baby } \\
\hline $29.2 \%$ & 61 & Agree \\
\hline $21.1 \%$ & 44 & Disagree \\
\hline $49.8 \%$ & 104 & Unsure \\
\hline
\end{tabular}

\section{TABLE 6: Awareness of EDA complications}


In this study result, there was a strong association between income and desirability to take EDA. As shown in Table 4, pregnant women with income less than 8000SAR (p-value 0.009) were more willing to use EDA than the others. On the other hand, there was no significant association between age, nationality, parity, and desirability to use EDA. The end result revealed that most of the pregnant women in this study (63.6\%) had positive desirability to take EDA.

Most women ( $\mathrm{n}=71 ; 34 \%)$ reported family and friends as their source of information about EDA, followed by doctors $(n=60 ; 28.7 \%)$, media $(n=56 ; 26.8 \%)$, nurses $(n=9 ; 4.3 \%)$, and antenatal class $(n=9 ; 4.3 \%)$.

In addition, pregnant women who received information from the antenatal class have better perception and awareness of EDA compared to those receiving information from other sources (100\%, $88.9 \%$ respectively). However, this relation was statistically insignificant ( $\mathrm{p}$-value $0.125,0.947$ respectively).

\section{Discussion}

Our study showed that the majority of participants (85.6\%) were aware of the EDA. A similar result was found in a study done in Riyadh, which showed that the participants were knowledgeable regarding EDA [10]. In contrast, a study done in Abu Dhabi in 2015 showed that women are not well informed about EDA and so they do not consider it [11]. Moreover, there was no relation found between the awareness of EDA and age, nationality, income, and parity ( $\mathrm{p}$-value $0.544,0.113,0.349,0.702$ respectively).

Of the women in our study population, 80.4\% were aware about the complication of using EDA for labor pain. This was contrary to study findings by Ezeonu et al., which showed that majority of women (72.41\%) had no knowledge about the complication of EDA [2]. We found that the majority of women agreed that EDA causes back pain and headache. This finding is similar to what was found in a Saudi study that was done in 2018 [12], unlike the conclusion of another study that was done among women from Australia and the United Kingdom, where they found that women in Australia have greater awareness about epidural infection and nerve damage [13].

The overall perception regarding EDA was positive in $87.6 \%$ of participants, which is higher by approximately $37 \%$ than the result of a Saudi study conducted in 2018 [12]. This could indicate that the population is becoming more educated toward EDA. A study in Townsville, Australia, showed that $44 \%$ of participants disagreed that they would never use EDA, while $56 \%$ were unsure about whether EDA helps with labor progression, and 63\% agreed that they were worried about the possibility that it will affect their ability to walk and move around [8]. These results were similar to our study with a small difference in the percentages (Table 3). In two previous studies, it was seen that most of the participants in Saudi Arabia and Pakistan were concerned about backache associated with EDA [14,12]. Similarly, in this study, back pain if using EDA was the biggest concern.

When it comes to EDA desirability, only $63.6 \%$ of pregnant women showed willingness to take EDA. In a study done in Ludhiana, desirability and willingness to take EDA (96.7\%) were significantly higher than our findings [2]. Interestingly, we found that pregnant women with income less than 8000SAR (p-value 0.009) were more willing to use EDA. We also found that age, nationality, and parity did not affect desirability to have EDA in labor. In contrast, a previously published study in India found that unwillingness and desire for epidural analgesia were closely linked to the gravida status [15].

Logically, we found that pregnant women who had a satisfactory experience with EDA (36, 67.9\%) are more willing to use it again compared to those with unsatisfactory experience (p-value 0.000). However, only $28.6 \%$ of pregnant women who had not used EDA in the past would like to use it in future. In addition, the reasons for low desirability for EDA were due to fear of side effects. This end result is similar to another study done in Nigeria, which concluded that $95 \%$ of the respondents who took EDA were satisfied with the experience and desired to take it again [2]. However, only 70\% of those who had not used EDA expressed the desire to use it. Some of the reported causes for the lack of desirability to using EDA includes fear of side effects, cost, and experiencing natural labor.

The most common source of information regarding EDA was the family and friends (34\%) followed by physicians (28.7\%), media (26.8\%), nurses (4.3\%), and antenatal class (4.3\%). This result is similar to a study done in Saudi Arabia where they found that the most common source of information regarding EDA was friends and relatives (67\%), previous labor experience (16\%), media (8\%), and books (2\%) respectively [12]. Only $39.1 \%$ of participants agreed that they have received adequate information on various forms of pain relief in labor including EDA. Therefore, antenatal care programs should include educational sessions about different types of pain relief during labor including EDA.

\section{Application}

Using the result of this research, an antenatal care program should include a discussion between pregnant women and a certified healthcare provider about EDA, its side effects, potential complications and alternatives. 


\section{Limitations and recommendations}

As the study was conducted between November and December 2020, the number of patients was restricted due to the COVID-19 pandemic. Moreover, this study took place in a tertiary hospital where the cases were more complicated; therefore, the participants were more knowledgeable. A suggestion is to conduct further research among pregnant women from different levels of healthcare systems including primary, secondary, and tertiary health care facilities.

In this study, most pregnant women received their sources of information from family, friends, or social media. This could influence the awareness, perception, and desirability of EDA. Therefore, we recommend giving antenatal educational programs for pregnant women who attend the clinic about possible pain management in labor including EDA. In addition, healthcare providers should put more effort on social media and provide the community with evidence-based information about possible methods of pain relief during labor since social media has a great influence in the community these days.

\section{Conclusions}

This study highlights the importance of labor pain management policies and patients' education. Although our study results demonstrate that the majority of pregnant women were aware of EDA and also had a positive perception and desirability toward using EDA for labor pain, there is still a good number of women who have a lack of awareness and perception toward EDA. These women may have more intense labor pain that will negatively affect their labor experience and make it less enjoyable. Therefore, having a national policy and guidelines on labor pain management is crucial to improving labor experience and maternal care in Saudi Arabia. Furthermore, education about different types of labor pain analgesia, especially EDA, should be included early in an antenatal care program.

\section{Additional Information}

\section{Disclosures}

Human subjects: Consent was obtained or waived by all participants in this study. Imam Abdulrahman bin Faisal University IRB issued approval IRB-UGS-2020-01-291. The application was reviewed and approved at Imam Abdulrahman bin Faisal University IRB through an expedited review on Tuesday, October 20, 2020. . Animal subjects: All authors have confirmed that this study did not involve animal subjects or tissue. Conflicts of interest: In compliance with the ICMJE uniform disclosure form, all authors declare the following: Payment/services info: All authors have declared that no financial support was received from any organization for the submitted work. Financial relationships: All authors have declared that they have no financial relationships at present or within the previous three years with any organizations that might have an interest in the submitted work. Other relationships: All authors have declared that there are no other relationships or activities that could appear to have influenced the submitted work.

\section{References}

1. Alleemudder DI, Kuponiyi Y, Kuponiyi C, McGlennan A, Fountain S, Kasivisvanathan R: Analgesia for labour: an evidence-based insight for the obstetrician. Obstet Gynecol. 2015, 17:147-55. 10.1111/tog.12196

2. Ezeonu PO, Anozie OB, Onu FA, et al.: Perceptions and practice of epidural analgesia among women attending antenatal clinic in FETHA. Int J Womens Health. 2017, 9:905-11. 10.2147/IJWH.S144953

3. Thakur M, Sagar N, Tandon P: Knowledge and attitude regarding epidural analgesia among expectant mothers. Int J Reprod Contracept Obstet Gynecol. 2017, 6:1929-31. 10.18203/2320-1770.ijrcog20171951

4. Vincent RD Jr, Chestnut DH: Epidural analgesia during labor. Am Fam Physician. 1998, 58:1785-92.

5. Li CJ, Xia F, Xu SQ, Shen XF: Concerned topics of epidural labor analgesia: labor elongation and maternal pyrexia: a systematic review. Chin Med J (Engl). 2020, 133:597-605. 10.1097/CM9.0000000000000646

6. ACOG Committee Opinion \#295: pain relief during labor. Obstet Gynecol. 2004, 104:213.

7. Intrapartum care for healthy women and babies. National Institute for Health and Care Excellence, London, UK; 2014. https://www.nice.org.uk/guidance/cg190/resources/intrapartum-care-for-healthy-women-andbabies-pdf-35109866447557.

8. Quach D, Woolley T, Pandit T, Rane A, Ray RA: Women's epidural decision-making in labour: a Townsville perspective. Aust N Z J Obstet Gynaecol. 2020, 60:919-27. 10.1111/ajo.13199

9. Fawaz M, Malas S: Lebanese women's awareness and attitude toward epidural anesthesia during labor. Data Brief. 2018, 19:530-4. 10.1016/j.dib.2018.05.051

10. Mohamed H, Alqahtani J, Almobaya N, Aldosary M, Alnajay H: Women's awareness and attitude toward epidural analgesia. J Biol Agric Healthc. 2013, 3:46-52.

11. Edwards G, Ansari T: A survey of women's views of epidural analgesia in the Middle East . Journal of Asian Midwives. 2015, 2:34-41.

12. Alsharidah DS, Alhuzaimi FI: Knowledge and attitude of Saudi women toward painless labor, and misconception about the risks and complications. Int J Adv Res (Indore). 2018, 6:1440-9. 10.21474/IJAR01/6575

13. Bethune L, Harper N, Lucas DN, Robinson NP, Cox M, Lilley A, Yentis SM: Complications of obstetric regional analgesia: how much information is enough?. Int J Obstet Anesth. 2004, 13:30-4. 10.1016/S0959289X(03)00102-X

14. Iqbal A, Saleem H, Akram N, Wasim A: A survey on perception of epidural in labouring women . Pakistan J Medical Health Sci. 2020, 14:16-19. 


\section{Cureus}

15. Kamakshi G, Anju G, Tania S, Priyanka G, Kamya B, Gegal P, Priyanka C: Epidural analgesia during labor: attitudes among expectant mothers and their care providers. Anesth Essays Res. 2018, 12:501-5. 10.4103/aer.AER_48_18 